\title{
A INTRODUÇÃO DA TILÁPIA DO NILO NO MUNICÍPIO DE MACAPÁ-AP E SUAS IMPLICAÇÕES PARA OS ECOSSISTEMAS REGIONAIS
}

\author{
Francisco Jardel LimaMoyses ${ }^{(a)}$,Caio Cesar Pantoja Brito ${ }^{(b)}$, Renata dos Santos ${ }^{(c)}$ \\ ${ }^{(a)}$ Departamento de Filosofia e Ciencias Humanas, Universidade Federal do Amapá, jardel_moyses@ hotmai.com

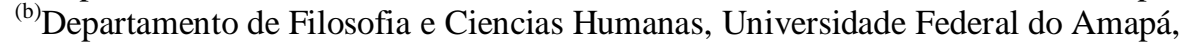 \\ caiopantojabrito@hotmail.com \\ ${ }^{(c)}$ Departamento de Filosofia e Ciencias Humanas, Universidade Federal do Amapá, renataunifap@ gmail.com
}

\section{EIXO: BIOGEOGRAFIA, MANEJO DE ÁREAS NATURAIS E ROTEGIDAS: CONSERVAÇÃO DA BIODIVERSIDADE}

\begin{abstract}
Resumo:
O trabalho versa analisar a ocorrência da tilápia do Nilo nas áreas de ressaca da cidade de Macapá e as implicações deste animal exótico sobre as espécies nativas no meio em questão. A presença destaespécie nos ecossistemas (ressaca) proporciona perigo a fauna local, sendo um agente hospedeiro de parasitas e competem por alimento e território, apresenta rápida procriação e rusticidade na adaptação a novos ambientes. Assim a presença da tilápia nas áreas de ressacas representa uma grande ameaça para a biodiversidade nativa regional já que a sua presença nas ressacas pode estar ligada a diminuição de peixes nativos. Dados indicam a presença dessa espécie em várias áreas de ressaca do município, associada a soltura indevida e/ou fuga de piscicultura localizam as margens de igarapés.
\end{abstract}

Palavras-chave:Áreas de ressaca;espécie invasora; biodiversidade.

\section{Introdução}

A piscicultura no Estado do Amapá é uma atividade que ocorre a menos de 30 anos, a qual engloba a criação de espécies nativas e exóticas, necessitando de manejo, estrutura e local adequado à cada espécie. De acordo com Gama (2008), a primeira espécie exótica com fins lucrativos a ser cultiva no Estado foi a Oreochromisniloticus, nome vulgar da tilápia do Nilo, cultivada no Brasil desde de 1971e trazido ao Amapá no ano de 1994, devido as suas características de adaptabilidade, rusticidade e de grande capacidade reprodutiva. Fatores que a tornaram a espécie mais cultivado no Brasil (RASGUIDO \& LOPES, 2004).

O Brasil apresenta o cultivo de três espécies de tilápias, Tilapiarendalli, a Sarotherodonurolepishornorumea tilápia do NiloOreochromisniloticus. Entre as três espécies mencionadas a tilápia do Nilo, é a espécie mais utilizada na aquicultura - processo de produção em cativeiro de organismos com hábitat predominantemente aquático (Kubitz, 2012). A tilápia do Nilo 
apresenta uma boa aceitação no mercado consumidor brasileiro, sendo levada para o estado do Amapá, na tentativa de ganhar mercado, o que não ocorreu devido a rica diversidade de peixe da região, tornando o seu cultivo marginalizado nas pisciculturas, que não atendiam as regras de manejo e confinamento, facilitando a fugas destes e até solturas ilegais da espécie nos ambientes de ressaca(GAMA, 2008).

A área de ressaca é um termo regional que nomeia as áreas alagadas, comuns no estado do Amapá. De acordo com Néri (2004), "é uma expressão regional empregada para designar um ecossistema típico da zona costeira do Amapá". Segundo Takiyama\& Silva (2004) "São áreas encaixadas em terrenos do quaternário que se comportam como reservatórios naturais de água, caracterizando-se como um ecossistema complexo e distinto". Além disso, sofrem os efeitos da ação das marés, por meio da rede formada de canais e igarapés e do ciclo sazonal das chuvas.

O objetivo deste trabalho consiste emanalisar a ocorrência da tilápia do Nilo nas áreas de ressaca da cidade de Macapá e as implicações deste animal exótico sobre as espécies nativas no meio em questão. Considerando que existe legislação que proíba a criação e/ou estabeleça normas para a criação, recriação e comercialização de peixes exóticos, tal como a Portaria n. $^{\circ} 145-\mathrm{N}$, de 29 de outubro de 1998, editada pelo IBAMA, que estabelece em seu art. $1^{\circ}$ e $3^{\circ}$ a política de fiscalização.

\section{Metodologia}

A pesquisa contou com um levantamento bibliográfico abordando a temática de animais exóticos, invasores e ecossistemas regionais. Diante da biodiversidade e rica malha hídrica do estado do Amapá a pesquisa se concentrou nas áreas de ressacas da cidade de Macapá, que estão ligadas ao Igarapé da Fortaleza afluente do Rio Amazonas, assim foram selecionadas seis áreas a saber; Ressaca do Zerão, Ressaca do Congós, Ressaca da Universidade, Ressaca Muca, Ressaca Alvorada e Lagoa dos Índios Através de trabalho de campo foi possível fazer observação, registro fotográfico e captura de indivíduos, sendo estabelecido a captura de 50 indivíduos de peixes independente da espécie para cada ressaca. Para isso foi utilizado malhadeira (rede de arrasto) tarrafa e anzóis, sendo capturado o total de 300 indivíduos de peixe. Após a captura, os peixes foram levados ao laboratório de Zoologia aquática da Universidade Estadual do Amapá para biometria e analise de parasitas, utilizando para isso o estéreo microscópico e microscópio de luz comum.Todos os dados foram tabulados, analisados e transformados em tabela e gráfico.

\section{Resultado e Discussão}




\subsection{Dispersão e dominância das Tilápias do Nilo sobre as espécies nativas nas áreas de Ressacas}

No trabalho de campo foram capturadas 16 espécies de peixe, incluído a espécie da tilápia. As espécies encontradas foram subdivididas em 09 grupos que apresentavam o mesmo nome vulgar (Tabela 01). Com isso foi contabilizado em nomes vulgares, 171 tilápias do Nilo; 87 indivíduos do gênero (Pterophyllum) vulgo acará; 03 jeju; 08 tamoatá, 04 apaiarí; 08 acarí; 04 uéua; 03 traíra e 08 piaba ou matupiri como também é conhecido.

Tabela 1- distribuição das espécies nativas e tilápia da Nilo nas áreas de ressaca

\begin{tabular}{|c|c|c|c|c|c|c|c|c|}
\hline Nome cientifico & Nome & & & & Ressaca & & & \\
\hline Espécies & Grupos & Muca & Congos & Zerão & $\begin{array}{l}\text { Nava } \\
\text { Esperança }\end{array}$ & $\begin{array}{l}\text { Lago dos } \\
\text { índios }\end{array}$ & Universidade & Total \\
\hline Oreochromisniloticus & $\begin{array}{l}\text { Tilápia } \\
\text { do Nilo }\end{array}$ & 50 & 34 & 49 & 18 & 02 & 18 & 171 \\
\hline Gênero Pterophyllum & Acarás & - & 07 & 01 & 29 & 26 & 24 & 87 \\
\hline Hoplerythrinussp. & Jeju & - & 01 & - & - & 01 & 02 & 04 \\
\hline $\begin{array}{l}\text { Hoplosternumsp. } \\
\text { Callichthyscallichthys }\end{array}$ & Tamoatá & - & 02 & - & 01 & 03 & 02 & 08 \\
\hline Astronotusocellatus & Apaiarí & - & 01 & - & - & 03 & - & 04 \\
\hline $\begin{array}{l}\text { Hypostomussp. } \\
\text { Ancistrussp. }\end{array}$ & Acarí & - & 04 & - & 01 & - & 02 & 07 \\
\hline Acestrorhynchussp. & Uéua & - & - & - & - & 5 & - & 05 \\
\hline Astyanaxabramis & $\begin{array}{l}\text { Piaba, } \\
\text { Matupiri }\end{array}$ & - & - & - & - & 08 & - & 08 \\
\hline Hopliasmalabaricus & Traíra & - & 01 & - & 01 & 02 & 02 & 06 \\
\hline Total de indivíduos & & $\mathbf{5 0}$ & 50 & $\mathbf{5 0}$ & $\mathbf{5 0}$ & 50 & 50 & 300 \\
\hline
\end{tabular}

Fonte: Dados da pesquisa

Os resultados apresentam que 57\% dos peixes pescados nas áreas de ressaca eram tilápias, e menos da metade eram outras espécies, inclusive da mesma família das tilápias (Cichlidae), tais como o acaras (29\%) e o apaiarí (1,33\%), que junto representam 30,33\% dos peixes capturados, sendo as espécies que mais competem com as tilápias (figura 01). Já as espécies que são consideradas predadoras Hoplerythrinussp e Hopliasmalabaricus (Jeju e Traíra), aparecem com menos frequência na captura totalizando juntas 3,33\%, o que aumenta ainda mais a possibilidade das tilápias chegarem à fase adulta. Outro fator importante é que também a tilápia preda os ovos, larvas e alevinos de seus predadores, podendo ocasionar desequilíbrio ecológico nestas áreas. 
Nas áreas da ressaca do Muca, Zerão e Congós as tilápias apresenta uma prevalência maior de que nas outras áreas de ressaca. Porém todas as áreas estudadas foram encontradas a espécie, isto mostra que apesar de existir barreiras (biológicas, geográficas e outras) que impedem as tilápias de se expandirem para outros locais, elas estão conquistando território, se estabelecendo e se expandindo para outras áreas, e isso fica cada vez mais nítido.

Segundo Gama (2008) e Tavares-Dias (2011) os primeiros registros de escapes intencionais e acidentais de tilápias no estado do Amapá, ocorreram nos anos 2000. Isto mostra que em mais ou menos 15 anos esta espécie de peixe vem se estabelecendo nestes ambientes e proliferando. Nas áreas de ressacas do Congos, Zerão e Muca pode-se considerar que há uma superpopulação da espécie, considerando que o tamanho e peso do indivíduo são características indicativas de competição. Das 171 tilápias capturadas nenhuma apresentou peso superior a $500 \mathrm{~g}$ e tamanho superior a $25 \mathrm{~cm}$, isso é um indicio de que nestes locais está ocorrendo uma superpopulação e os indivíduos tende a ficarem cada vez menores. A competição por alimento é promovida e a falta deste faz que muitos peixes não ganhem massa muscular e aumento da carcaça ou seja, a densidade de indivíduos influencia na taxa de crescimento da espécie.

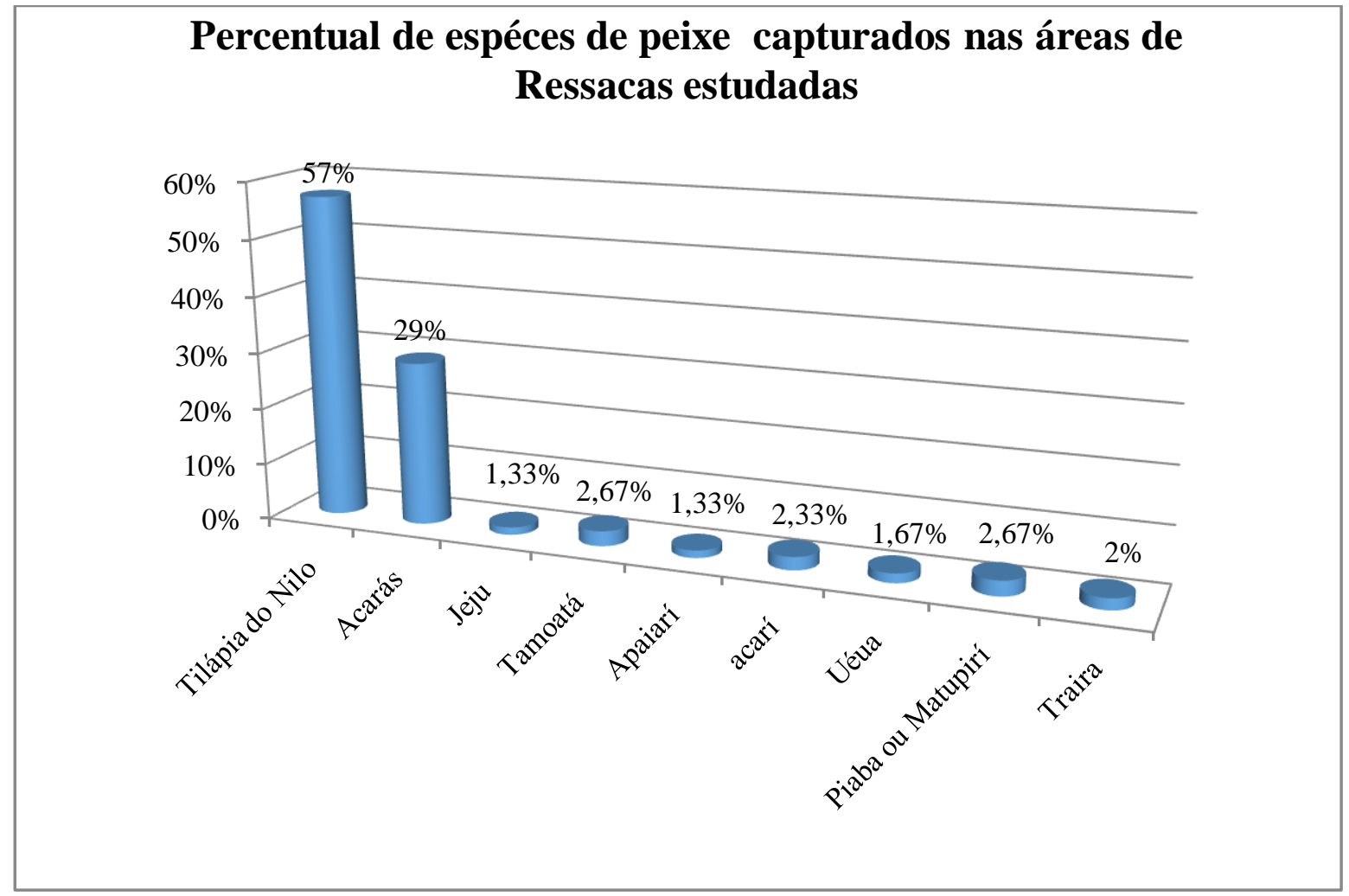

Figura 1- Gráfico com o percentual de espécimes dos peixes capturados nas seis áreas de ressacas estudadas 
O peso das tilápias capturado variou de $31,5 \mathrm{~g}$ a $115,4 \mathrm{~g}$, tendo como média $92,45 \mathrm{~g}$, o tamanho variou entre $4,9 \mathrm{~cm}$ a $17,2 \mathrm{~cm}$, enquanto que a média é de $12,1 \mathrm{~cm}$. Os resultados indicam uma necessidade de plano de manejo para controle desse peixe invasor, o que evitará a extinção de muitas espécies de peixes e outros organismos nativos. Estes dados poderão ser ferramentas indispensáveis para a tomada de decisão em qualquer esfera governamental (municipal, estadual e federal), evitando prejuízo futuro ao meio ambiente.

\section{Considerações Finais}

A tilápia do Nilo foi introduzida em muitos lugares no mundo, com a finalidade de diminuir a pressão aos cardumes naturais, exercida por pessoas que tem na pesca seu meio de vida, além de suprir a demanda de alimento. Isto somando ao baixo custo de investimento, fez dessa espécie de peixe uma alternativa econômica em muitos lugares, inclusive em Macapá - AP.

Devido as tilápias terem uma ampla tolerância às variações ambientais, alta taxa de reprodução e crescimento populacional, além apresentarem facilidade de se adaptarem à vários tipos de cultivo. Tudo isso fez com que o cultivo da tilápia do Nilo torna-se o modelo zootécnico preferida para estocagem em muitos lugares do Brasil. Porém, as mesmas características que a tornam uma espécie atrativa economicamente para alavancar a piscicultura nacional tornam essa espécie uma invasora bem-sucedida, com grande potencial de se tornar uma praga nos ambientes aquáticos onde é introduzida. Os resultados mostram uma série de problemas quanto à criação de tilápia contrariando a ideia inicial.

As tilápias trazem uma serie de mudança aos ecossistemas naturais como, por exemplo, nas áreas de ressacas, tais como a redução na abundância de certos microcrustáceos planctônicos, e com isso um aumento na biomassa de algas e a diminuição dos peixes nativos. Portanto, os riscos ambientais associados às introduções de tilápias devem ser analisados, verificando até mesmo se é relevante sua criação, quanto os possíveis benefícios socioeconômicos de sua criação, podendo ser substituído por criação de peixes nativos com valor econômico.

\section{Bibliografia}

GAMA, C. S. A criação de tilápia no estado do Amapá como fonte de risco ambiental. Acta Amazônico, vol. 38(3), $525-530,2008$.

KUBITZA, F.Tilápia:tecnologia e planejamento na produção comercial. Jundiaí: 2000. 
NERI, S. H. A. 2004. A utilização das ferramentas de geoprocessamento para identificação de comunidades expostas a hepatite A nas áreas de ressacas 15 municípios de Macapá e Santana/AP. 2004. 173f. Dissertação (Mestrado em Engenharia Civil/Recursos Hídricos) - Coordenação dos Programas de PósGraduação em Engenharia, Universidade Federal do Rio de Janeiro.

RASGUIDO, J. E. A. \& LOPES, J. D. S. “criação de peixes”, Viçosa-MG, CPT, 2004.

TAKIYAMA L.R., Silva A.Q., Costa W.J.P. \& Nascimento H.S. (2004). Qualidade das Águas das ressacas das bacias do Igarapé da Fortaleza e do Rio Curiaú. In: Takiyama L.R. \& Silva A.Q. da (orgs.). Diagnóstico das ressacas do Estado do Amapá: Bacias do Igarapé da Fortaleza e Rio Curiaú, Macapá-AP. Macapá: CPAQ/IEPA e DGEO/SEMA.

TAVARES-DIAS M. Piscicultura continental no estado do Amapá: diagnóstico e perspectivas. Boletim de Pesquisa e Desenvolvimento. Macapá, Brasil: Embrapa Amapá. 2011. 